\title{
On the Testicular Structures Found in the Ovaries of the "Cobalt" Rainbow Trout*1
}

\author{
Mikio OGURI*2 \\ (Received January 10, 1975)
}

\begin{abstract}
Testicular structures were detected in the ovaries of two specimens of the "cobalt" rainbow trout, obtained at the Shiga Prefectural Samegai Trout Experimental Station on July 25,1973 . In the ovary of one specimen (fish No. 3), the testicular cysts were occasionally detectable, and the cysts were filled with spermatogonia, spermatocytes and spermatids. Furthermore, in some cysts oocytes were intermingled with male germ cells in various spermatogenic stages. In the other specimen (fish No. 4), testicular structure was detected also, but only in one limited region of a histological preparation of the ovary. In all the three "cobalt" examined, ovarian germ layers were conspicuously hypertrophied and composed of many gonial germ cells.
\end{abstract}

The gonad of the "cobalt" rainbow trout seems to provide valuable research materials to elucidate the gonadal relationship to the pituitary gland of teleost, because the "cobalt" possesses only anomalous pituitary remnant, consisted mostly of prolactin-like cells and probably with few gonadotrops, as reported in the previous paper. ${ }^{1{ }^{1}}$

During the course of the histological examinations on the ovary of the "cobalt" rainbow trout, testicular structures were detected in two specimens of the "cobalt." In the normal rainbow trout, spontaneous hermaphroditism has been occasionally reported by some investigators. ${ }^{2-4}$ ) However, so far as I know no record has been reported on the hermaphroditism in the "cobalt" rainbow trout. Accordingly, this report deals with the results of the observation on the hermaphrodites.

\section{Materials and Methods}

Six fishes of "cobalt" variant of rainbow trout, Salmo gairdneri, were used in the present investigation. Among them, three fishes were classified as females by macroscopic observation. Table 1 shows the body length and weight, and gonad weight of these fishes. Also, six fishes (body weight, $155-180 \mathrm{~g}$; standard length, $21.5-23 \mathrm{~cm}$ ) of normal rainbow trout were used for comparison. These fishes were obtained from the Shiga Prefectural Samegai Trout Experimental Station, Maibara, Shiga Prefecture on July 25, 1973.

The gonads of these fishes were fixed in BouIN's fluid and embedded in paraffin. Paraffin sections were cut at $7 \mu$ and stained with the following methods; GoMORI's

*1 The outline of this report was presented at the autumn meeting of the Japanese Society of Scientific Fisheries, Kyoto, Japan, November, 1974

*2 Fisheries Laboratory, Faculty of Agriculture, Nagoya University, Nagoya, Japan（小梁幹郎：名古 屋大学贯学部水産学数室) 
Table 1. "Cobalt" rainbow trout used in the present investigation

\begin{tabular}{ccccc}
\hline \hline Fish No. & Sex & Body weight & Standard length & Gonad weight \\
\hline 1 & Male & $225 \mathrm{~g}$ & $21.0 \mathrm{~cm}$ & $0.07 \mathrm{~g}$ \\
2 & $"$ & $\prime \prime$ & 23.5 & 0.05 \\
3 & Female* & 160 & 19.0 & 0.10 \\
4 & $"{ }^{*}$ & 180 & 19.5 & 0.25 \\
5 & $\prime{ }^{*}$ & 20.0 & 0.06 \\
6 & Male & 220 & 20.5 & 0.09 \\
\hline
\end{tabular}

* Classified as females by macroscopic observation.

chrome-hematoxylin and phloxine, HeIDENHAIN's iron-hematoxylin and light green, MALLORY's triple stain, MAYER's acid hemalum and eosin, and PAS-MAYER's acid hemalum.

\section{Results}

The ovaries of all the three normal rainbow trouts used as controls contained the oocytes at the yolk-vesicular or earlier stages (Fig. 1). The maximum size of these oocytes was about $535 \mu$ in diameter. On the contrary, the ovaries of all the three "cobalt" rainbow trouts used in the present examination included only the oocytes at the perinuclear or earlier stages (Fig. 2). The maximum size of these oocytes was about $335 \mu$ in diameter. YAMAZAKI" also reported that the ovaries of "cobalt" did not contain the oocytes at more advanced stages than perinuclear one. On the other hand, spermatogenesis was observed in the testes of all the three normal rainbow trouts employed as controls, and spermatogonia, spermatocytes, spermatids and spermatozoa were seen in the testes (Fig. 3). However, the testes of all the three "cobalt" rainbow trouts contained usually only spermatogonia. Uncommonly the spermatocytes and spermatozoa were detected in the testis of "cobalt" (fish No. 2) (Figs. 4A and 4B).

During the course of this histological examination, the ovary with testicular structures was detected in one "cobalt" specimen (fish No. 3 in Table 1); in the ovary testicular cysts filled with the clusters of male germ cells in various spermatogenic stages were occasionally observed (Figs. 5-11). The presence of the spermatogonia, primary spermatocytes and spermatids was evident in these cysts (Figs 6-11). However, the secondary spermatocytes were rarely observed, probably due to the short period of this stage in the spermatogenesis of rainbow trout, as described by OoTA et $a l^{6)}$. Furthermore, so far as I examined, the spermatogenesis in the cysts seems to remain at the stage of spermatids and the cysts contain no spermatozoa. As an interesting result, the intermingling of oocytes with male germ cells in various spermatogenic stages was detected in some cysts (Figs. 10 and 11). This hermaphroditic specimen possessed only detached pituitary remnant located in the region ventral to the optic chiasma and dorsal to the upper pharynx (Figs. 12 and 13), as reported in the previous paper. ${ }^{1)}$ 
In the ovary of the other specimen (fish No. 4 in Table 1), I found a testicular cyst showing spermatogenesis only in one preparation from many ones examined (Figs. 14 and 15). However, in the ovary of the third specimen (fish No. 5 in Table 1), testicular structures could not be detected in any preparations investigated, though the germinal layers were conspicuously hypertrophied, containing many gonial germ cells (Fig. 16).

\section{Discussion}

Gonadal development in teleosts is said to be obviously different from that in the other higher vertebrates. ${ }^{7)}$ In these vertebrates, gonads are formed from the two components, cortex and medulla, which contributes female and male differentiations in gonadal germ cells, respectively. However, the teleostean gonad is said to develop only from a single primordium which corresponds to the cortex." Accordingly, in the "undifferentiated" gonochorists such as rainbow trout, the indifferent gonad develops first into an ovary-like gonad, and then about half number of the individuals becomes male fishes and does the other half female ones. ${ }^{8,9}$ In the present examination, intermingled state of male and female germ cells was detected in the same testicular cysts. This finding seems to indicate the possibility of sex differentiation in the later gonadal development of rainbow trout, an "undifferentiated" gonochorist.

Spontaneous hermaphroditism has been recorded in many species of teleosts belonging to the following eight orders: Clupeiformes, Cypriniformes, Gadiformes, Cyprinodontiformes, Gasterosteiformes, Channiformes, Perciformes and Pleuronectiformes.7, 10-12) As mentioned above, rainbow trout is said to be a species belonging to the "undifferentiated" gonochorists. ${ }^{8,9}$ Accordingly, spontaneous hermaphroditism has been occasionally reported by some investigators. ${ }^{2-4)}$ Furthermore, MRšlić ${ }^{8\rangle}$ reported the experimentally induced hermaphroditism in rainbow trout. All these cases of hermaphroditism in rainbow trout were confirmed only by macroscopic observations. In the present observation, all the three gonads of "cobalt" were first classified macroscopically as ovary. Finally, from the microscopic examination, the testicular structures were detected in the ovaries of two specimens of the "cobalt". Therefore, if microscopical examinations are conducted, more cases of spontaneous hermaphroditism may be detected in the rainbow trout, because this fish is an "undifferentiated" gonochorist. Similar spontaneous hermaphroditism has been reported in goldfish, Carassitus auratus ${ }^{13}$ and in Medaka, Oryzias latipes. ${ }^{14)}$

It is well known that the pituitary gland is indispensable for normal gametogenesis in teleosts. ${ }^{15-18}$ In female fish, the gland is implicated in vitellogenesis of oocytes. ${ }^{15,16)}$ Also, the transformation from spermatogonia into primary spermatocytes does not occur in the hypophysectomized male fish. ${ }^{16-18)}$ As reported in the previous paper, ${ }^{1 \text { ) the }}$ "cobalt" rainbow trout possesses only an anomalous pituitary remnant, consisted mostly 
of prolactin-like cells and probably with few gonadotrops. Therefore, it seems explainable that in the present examination the vitellogenesis did not occur in the ovary of the "cobalt" and the oocytes remained at the perinuclear or earlier stages, under the circumstance insufficient of the gonadotropin. On the other hand, how to explain the spermatogenesis in the "cobalt" ovary? One possibility is that the detached pituitary remnant may be capable of secreting gonadotropin, at least sufficient to the induction of the sporadic spermatogenesis in the "cobalt" ovary. This may be supported by the result that the spermatogenesis was uncommonly observed in the testis of "cobalt" (fish No. 2). In connection with this, SCHMIDT et al. ${ }^{19)}$ reported that the testis of rainbow trout was stimulated by lower dose of salmon gonadotropin than did in the ovary. At present, however, the cause of occurrence of testicular structures in the ovary of the "cobalt" remains still uncertain.

\section{Acknowledgement}

I am indebted to Mr. K. Nishnde and other staffs of the Shiga Prefectural Samegai Trout Experimental Station for kindly supplying me with normal and "cobalt" rainbow trouts.

\section{References}

1) M. Ogur1: This Bull., 40, 869-875 (1974).

2) I. MAtsui: Kagaku, 6, 506-507 (1936) (In Japanese).

3) E. D. GibBs: Calif. Fish Game 42, 229-231 (1956).

4) A. J. Ross, W. T. Yasutake, and G. R. White: Trans. Amer. Fish. Soc., 92, 313-315 (1963).

5) F. YAMAZAKI: This Bull, 40, 17-25 (1974) (In Japanese).

6) I. Oota, K. Yamamoto, K. Takano and T. Sakaguchi: ibid., 31, 597-605 (1965).

7) J. W. ATZ: in "Intersexuality in Vertebrates including Man" (ed. by C. N. ARmstrong and A. J. Marshall), Academic Press, New York, 1964, pp. 145-232.

8) W. Mršić: Roux Arch. Entwicklungsmech. Organ., 98, 129-209 (1923).

9) T. Yamamoto: in "Fish Physiology" (ed. by W. S. Hoar and D. J. Randall) Vol. III, Academic Press, New York, 1969, pp. 117-175.

10) C. E. Dawson: Gulf Research Reports, 1, 308-399 (1964).

11) C. E. Dawson: ibid., 2, 169-176 (1966).

12) C. E. Dawson: ibid., 3, 215-239 (1971).

13) H. Takahashi: Jap. J. Ichthyol., 17, 67-73 (1970).

14) S. Kasuga: Zool. Mag., 82, 127-132 (1973) (In Japanese).

15) F. Yamazaki: Mem. Fac. Fisheries, Hokkaido Univ., 13, 1-64 (1965).

16) J. M. Dodd: Gen. Comp. Endocrinol. Suppl., 3, 675-687 (1972).

17) B. I. Sundararaj and S. K. NAYYAR: Gen. Comp. Endocrinol., 8, 403-416 (1967).

18) B. Lofts, G. E. Pickford and J. W. Atz: Biol. Bull., 34, 74-86 (1968).

19) P. J. Schmidt, B. S. Mitchell, M. Smith and H. Tsuyuki: Gen. Comp. Endocrinol, 5, 197-206 (1965). 


\section{Explanation of figures}

Fig. 1. Ovary of normal rainbow trout (body length, $22 \mathrm{~cm}$; body weight, $180 \mathrm{~g}$ ). $\times 95$

Fig. 2. Ovary of "cobalt" rainbow trout. Fish No. 5. $\times 95$

Fig. 3. Testis of normal rainbow trout (body length, $22 \mathrm{~cm}$; body weight, $160 \mathrm{~g}$ ). $\times 380$

Fig. 4. Testis of "cobalt". Fish No. 2. Arrows show spermatocytes (4A) and spermatozoa (4B). $\times 380$

Figs. 5-11. Ovaries of "cobalt". Fish No. 3. Arrows in Fig. 5 show testicular cysts. Gc in Fig. 7, gonial germ cells. Fig. 8. Primary spermatocytes in post-synaptic stages and spermatids are seen in upper and under sides, respectively. Fig. 9. Primary spermatocytes and spermatids are seen in right and left sides, respectively. Figs. $5-7 . \times 380$, Figs. 8 and $9 . \times 1500$ (oil immersion), Fig. 10. $\times 345$, Fig. 11. $\times 380$

Fig. 12. Midsagittal section through the ventral brain region of "cobalt". Fish No. 3, Sv, Saccus vasculosus. $\times 485$

Fig. 13. Detached pituitary remnant of "cobalt'. Fish No. 3. Ct, cartilage; Mt, muscular tissue; $\mathrm{Pb}$, parasphenoid bone; $\mathrm{Pr}$, pituitary remnant. $\times 50$

Figs. 14 and 15. Ovary of "cobalt". Fish No. 4. Arrows show spermatids. Fig. $14 . \times 160$ and Fig. 15. $\times 650$.

Fig. 16. Ovary of "cobalt". Fish No. $5 . \times 380$.

Fig. 1. PAS and MAYER's acid hemalum stain, Figs. 2-6, 9, 12, 14 and 15. MAYER's acid hemalum and eosin stain, Fig. 7. Mallory's triple stain, Figs. 8, 11 and 16, HeIDENHAIN's iron-hematoxylin and light green stain, and Figs. 10 and 13. Gomori's chrome-hematoxylin and phloxine stain. 


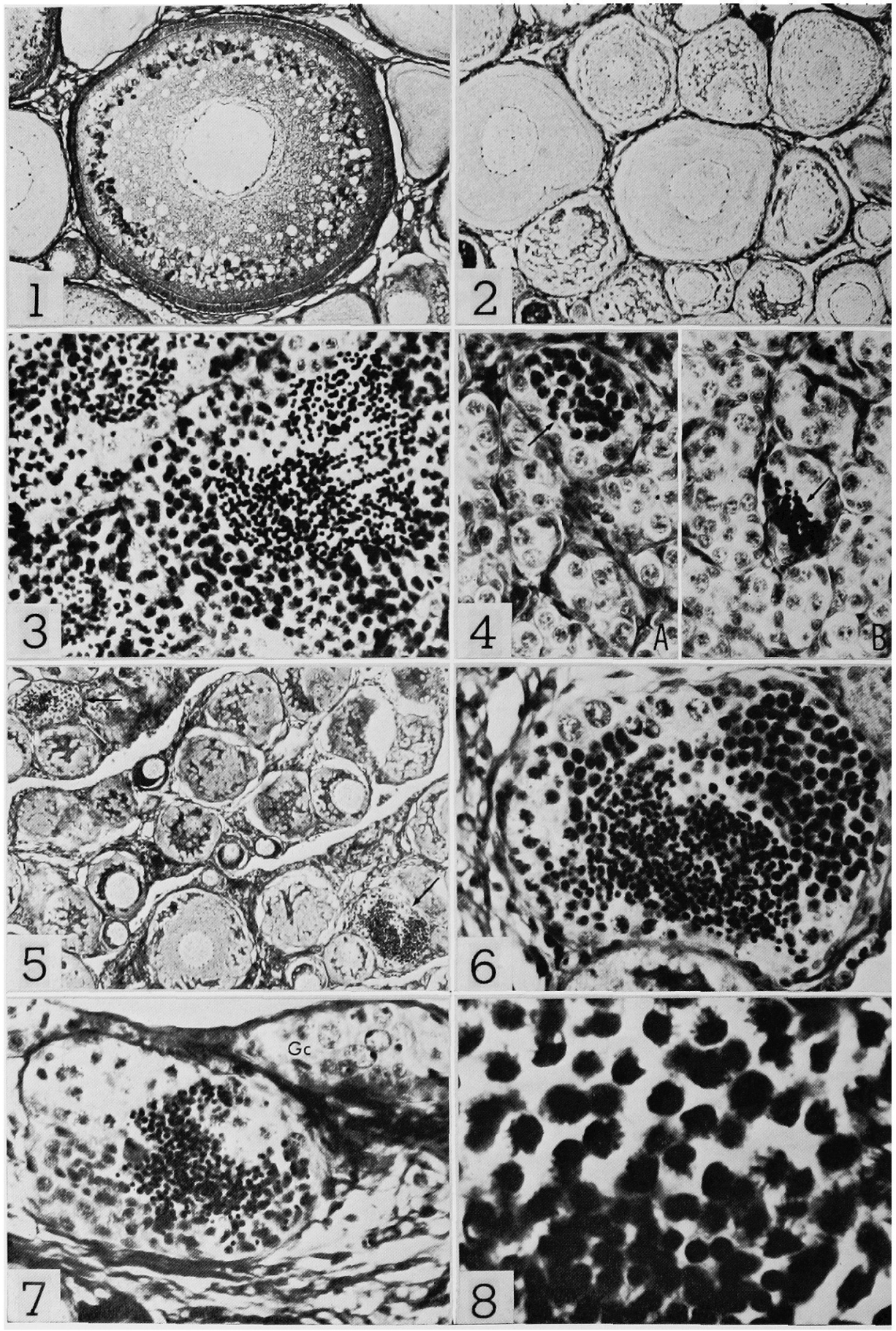




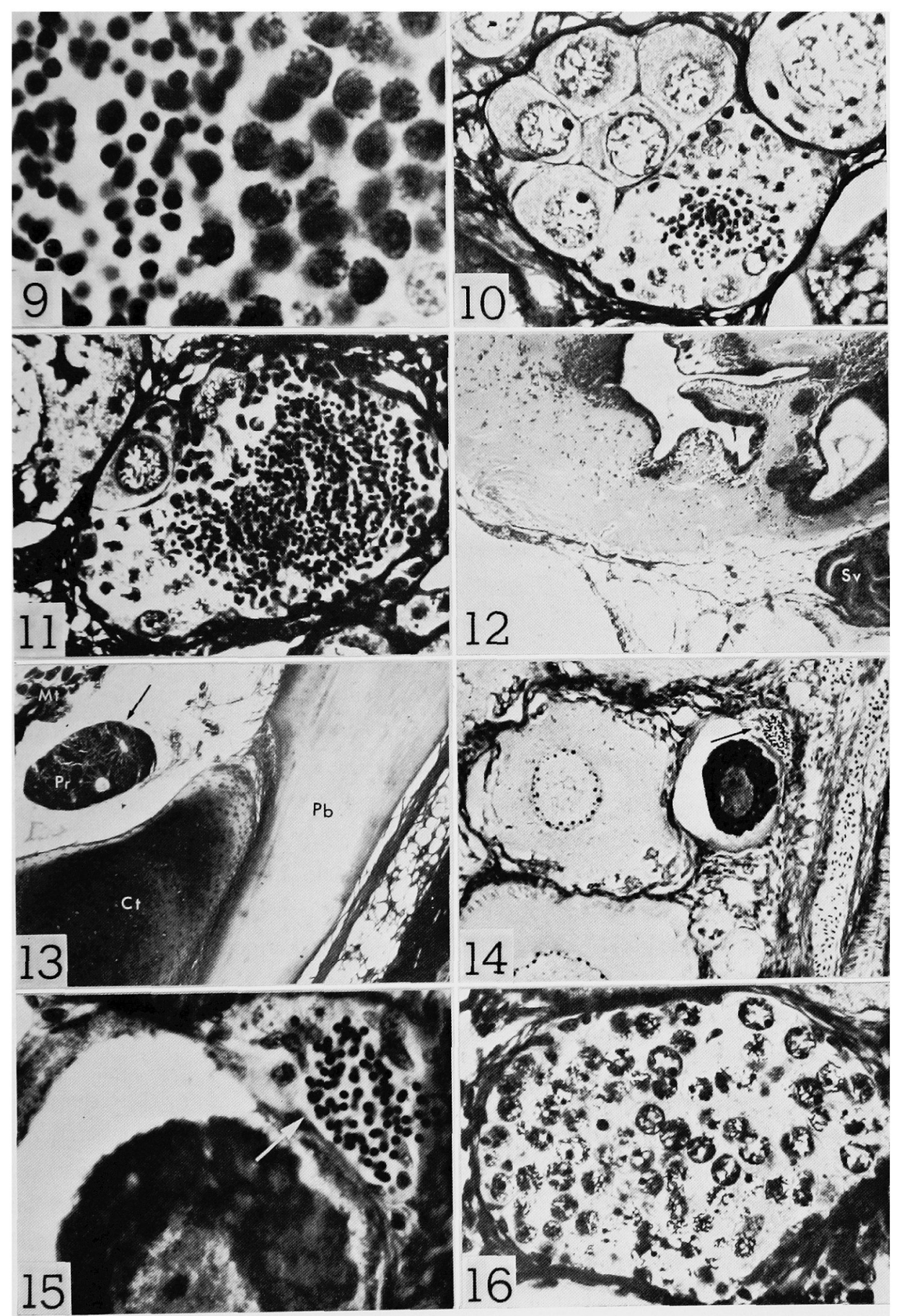

